OPEN ACCESS

Edited by:

Jian-ye Zhang,

Guangzhou Medical University, China

Reviewed by:

Anubhab Mukheriee,

Principal Scientist, Hyderabad, India

Silvio Naviglio,

University of Campania Luigi

Vanvitelli, Italy

*Correspondence:

Chao Liang

liangc@sustech.edu.cn

Aiping Lu

aipinglu@hkbu.edu.hk

${ }^{+}$These authors have contributed equally to this work

Specialty section: This article was submitted to Cancer Molecular Targets and Therapeutics,

a section of the journal

Frontiers in Oncology

Received: 25 December 2021 Accepted: 07 February 2022

Published: 04 March 2022

Citation:

Xie D, Wang Z, Li J, Guo D-a, Lu A and Liang C (2022) Targeted Delivery of

Chemotherapeutic Agents for

Osteosarcoma Treatment.

Front. Oncol. 12:843345.

doi: 10.3389/fonc.2022.843345

\section{Targeted Delivery of Chemotherapeutic Agents for Osteosarcoma Treatment}

\author{
Duoli Xie ${ }^{1,2,3 \dagger}$, Zhuqian Wang ${ }^{1,2,3 \dagger}$, Jie $\mathrm{Li}^{4}$, De-an Guo ${ }^{5}$, Aiping $\mathrm{Lu}^{2,3,6,7 *}$ \\ and Chao Liang ${ }^{1,2,3 *}$
}

1 Department of Biology, School of Life Sciences, Southern University of Science and Technology, Shenzhen, China, 2 Institute of Integrated Bioinfomedicine and Translational Science (IBTS), School of Chinese Medicine, Hong Kong Baptist University, Hong Kong, Hong Kong SAR, China, ${ }^{3}$ Law Sau Fai Institute for Advancing Translational Medicine in Bone and Joint Diseases, School of Chinese Medicine, Hong Kong Baptist University, Hong Kong, Hong Kong SAR, China,

${ }^{4}$ Department of Laboratory Medicine, Peking University Shenzhen Hospital, Shenzhen, China, ${ }^{5}$ National Engineering Laboratory for Standardization of Traditional Chinese Medicine, Shanghai Institute of Materia Medica of the Chinese Academy of Sciences, Shanghai, China, ${ }^{6}$ Institute of Arthritis Research in Integrative Medicine, Shanghai Academy of Traditional Chinese Medicine, Shanghai, China, ${ }^{7}$ Guangdong-Hong Kong-Macau Joint Lab on Chinese Medicine and Immune Disease Research, Guangzhou, China

Since osteosarcoma (OS) is an aggressive bone cancer with unknown molecular pathways of etiology and pathophysiology, improving patient survival has long been a challenge. The conventional therapy is a complex multidisciplinary management that include radiotherapy, chemotherapy which followed by surgery and then post-operative adjuvant chemotherapy. However, they have severe side effects because the majority of the medicines used have just a minor selectivity for malignant tissue. As a result, treating tumor cells specifically without damaging healthy tissue is currently a primary goal in OS therapy. The coupling of chemotherapeutic drugs with targeting ligands is a unique therapy method for OS that, by active targeting, can overcome the aforementioned hurdles. This review focuses on advances in ligands and chemotherapeutic agents employed in targeted delivery to improve the capacity of active targeting and provide some insight into future therapeutic research for OS.

Keywords: osteosarcoma, targeted delivery, chemotherapeutic agents, ligand-based delivery systems, antibodies

\section{INTRODUCTION}

Osteosarcoma (OS) is a relatively rare malignant mesenchymal origin bone cancer that $70 \%-80 \%$ of OS patients are adolescents and young adults and is distinguished by the formation of immature osteoid extracellular matrix (1). The disease has a 1-3 case per 1,000,000 population incidence and accounts for $20 \%$ of all primary malignant bone tumors in the world (2). OS is most common in the metaphysis of long, tubular bones like the proximal humerus, distal femur, and proximal tibia. It is very rare in the spine, pelvis, and sacrum, but it can be found in the metaphysis of some other bones (3). More than $85 \%$ of individuals with localized illness will develop a local or distant recurrence, most commonly in the lungs (85-90\%) (4). Clinically, the development of disease is marked primarily by local discomfort and swelling, with occasional joint dysfunction (5) (Figure 1). 


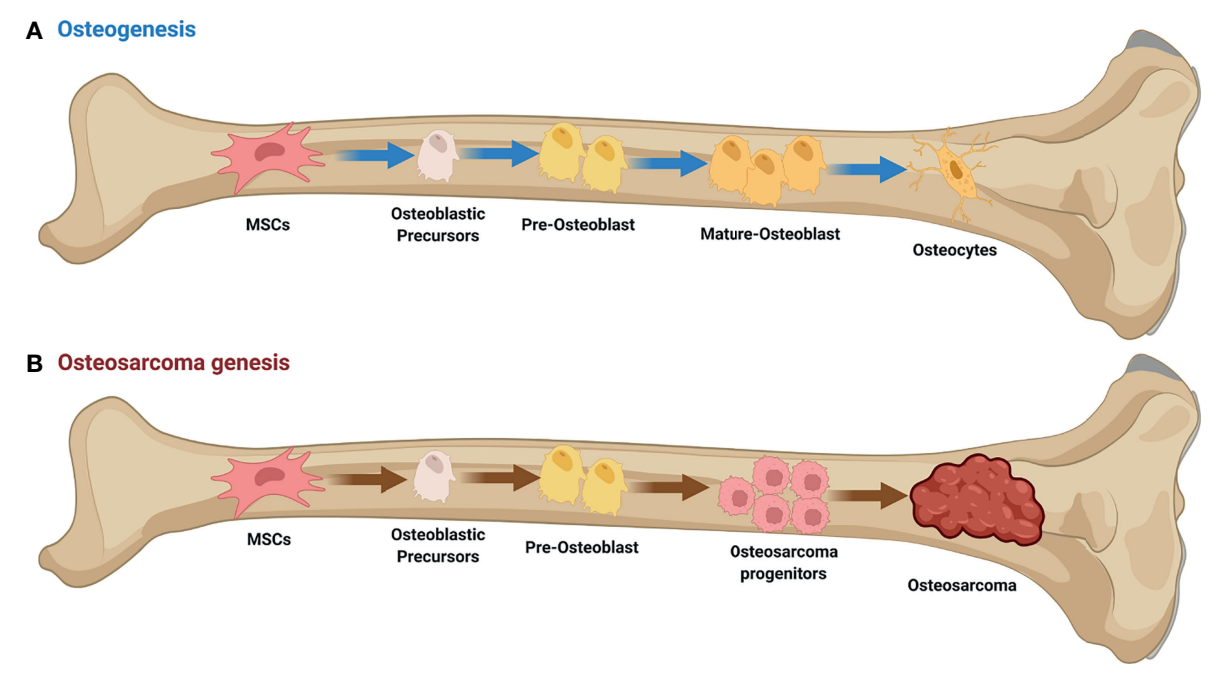

FIGURE 1 | Osteogenesis and Osteosarcoma genesis. (A) Initiation of osteogenic differentiation from mesenchymal stem cells (MSCs). MSCs are multipotent bone marrow cells that are capable of differentiating to bone (osteoblast/osteocyte), fat (adipocyte), and cartilage (chondrocyte) tissues. (B) Defects in osteogenesis lead to osteosarcoma genesis. Genetic alterations probably interfere with the normal osteogenic process, resulting in incompletely differentiated osteoblasts or osteocytes in bone. These defects disrupt the balance between proliferation and differentiation, and may cause a group of cells to display uncontrolled cell proliferation.

Osteosarcoma progenitors may arise from these cells and expand to form osteosarcoma. This figure was created with BioRender.com.

Chemotherapy, followed by total surgical resection and then post-operative adjuvant chemotherapy as well as radiotherapy, is currently the standard treatment strategy for OS. Methotrexate (MTX), doxorubicin (DOX), cisplatin (CDDP), ifosfamide (IFO), and etoposide are commonly used chemotherapeutic agents recommended by The National Comprehensive Cancer Network guidelines, which increased the survival rate in patients with localized resectable tumors by up to $60-70 \%$ (1); However, most clinical applications of chemotherapeutics for patients with advanced and metastatic OS have been limited due to a lack of selectivity and sensitivity to tumor cells, toxicity towards normal cells, multidrug resistance (MDR), poor pharmacokinetic performance (6), and other factors that limit treatment efficacy and result in severe adverse effects on vital organs (7). With these combination therapy, the overall 5-year survival percentage for individuals with primary metastatic or relapsed cancer is less than 20\% (8). Despite numerous clinical trials over the last three decades, cure rates for those with OS have not considerably improved, and survival for patients with metastatic or recurrent disease remains bleak (9). In the meantime, there are many NCT clinical trials in progress, pending follow-up (Table 1).

As a result, the development of some new anticancer medicines with reduced toxicity and higher tumor-killing effectiveness is desirable in order to increase patient survival and quality of life (10). A potent treatment with rational delivery vehicle and a surface ligand are often included in a ligand-based drug delivery system (11). Drugs might be delivered to tumor sites by receptormediated endocytosis once the individual ligands have contacted the corresponding tissue in vivo, allowing for tailored distribution of unique effector molecules while reducing adverse effects (12). Ligands such as antibodies, aptamers, peptides (13), saccharide, vitamin, bisphosphonates (BP) $(14,15)$, hyaluronic acid (HA) (16) and folate (17) have been reported to be used in the development of OS targeted drug delivery systems that mediate delivery vehicle and drug interactions with and internalization into OS cells with high specificity and efficiency (7). Some of them have a strong affinity for hydroxyapatite and can be employed as ligand in bone (7). In terms of drug carrier, liposomes which Alec D. Bangham developed in 1965, served as the first therapeutic nanoparticles to receive FDA approval, are now the most widely used (18). Liposomes have been extensively explored since they are capable of holding both hydrophilic and lipophilic pharmaceuticals (19). Mepact-liposomal mifamurtide which had been commercialized by Takeda Pharmaceuticals in 2004, is indicated for the treatment of high-grade, nonmetastasizing, resectable osteosarcoma following complete surgical removal in children, adolescents, and young adults (20). For further development in the similar line of thought, liposomes combined with chitooligosaccharides with a disulphide linker were developed by Yin et al. (21); Similarly, a reduction-responsive liposome decorated with COS and functionalised with oestrogen has been synthesised to preferentially target MG63 cells (22); Haghiralsadat et al. synthesised a thermo- and $\mathrm{pH}$ - sensitive liposome for nanoformulation of DOX which could inhibit the proliferation of MG63 cells and reduce cytotoxicity to healthy bone cells (23). As above mentioned, the advantages of traditional anti-OS chemotherapy are expected to be overcome by these drug delivery systems. In this review, we will look at the different types of ligands that can specifically bind to the matching receptors in OS and cause receptor-mediated endocytosis. Furthermore, the drug conjugates produced by chemically conjugating drugs were explained using studies that were available. This will spark new ideas for the development of more effective therapeutic options. 
TABLE 1 | Ongoing NCT clinical trials of OS.

\begin{tabular}{|c|c|c|c|c|c|c|}
\hline $\begin{array}{l}\text { Clinical Trial } \\
\text { NCT No. }\end{array}$ & Phase & Title & $\begin{array}{l}\text { No. of } \\
\text { patients }\end{array}$ & $\begin{array}{l}\text { Status; Estimated } \\
\text { completion date }\end{array}$ & Cancer Type & Sponsor \\
\hline NCT01459484 & $\|$ & $\begin{array}{l}\text { ABCB1/P-glycoprotein Expression as Biologic } \\
\text { Stratification Factor for Patients with non metastatic } \\
\text { Osteosarcoma (ISG/OS-2) }\end{array}$ & 225 & $\begin{array}{l}\text { Active, not recruiting; } \\
\text { October } 30,2021\end{array}$ & $\begin{array}{l}\text { Non-metastatic extremity } \\
\text { high-grade osteosarcoma }\end{array}$ & $\begin{array}{l}\text { Italian Sarcoma } \\
\text { Group }\end{array}$ \\
\hline NCT03006848 & $\|$ & $\begin{array}{l}\text { A Phase II Trial of Avelumab in Patients with Recurrent } \\
\text { or Progressive Osteosarcoma }\end{array}$ & 19 & $\begin{array}{l}\text { Active, not recruiting; } \\
\text { January } 31,2023\end{array}$ & $\begin{array}{l}\text { Recurrent/Refractory } \\
\text { osteosarcoma }\end{array}$ & $\begin{array}{l}\text { St. Jude } \\
\text { Children's } \\
\text { Research } \\
\text { Hospital }\end{array}$ \\
\hline NCT04154189 & $\|$ & $\begin{array}{l}\text { A Study to Compare the Efficacy and Safety of } \\
\text { Ifosfamide and Etoposide with or Without Lenvatinib in } \\
\text { Children, Adolescents and Young Adults with Relapsed } \\
\text { and Refractory Osteosarcoma }\end{array}$ & 72 & $\begin{array}{l}\text { Active, not recruiting; } \\
\text { December } 31,2022\end{array}$ & $\begin{array}{l}\text { Relapsed or Refractory } \\
\text { Osteosarcoma. }\end{array}$ & Eisai Inc. \\
\hline NCT02484443 & $\|$ & $\begin{array}{l}\text { Dinutuximab in Combination with Sargramostim in } \\
\text { Treating Patients with Recurrent Osteosarcoma }\end{array}$ & 41 & $\begin{array}{l}\text { Active, not recruiting; } \\
\text { N.A. }\end{array}$ & $\begin{array}{l}\text { Metastatic Malignant } \\
\text { Neoplasm in the Lung } \\
\text { Metastatic/Recurrent } \\
\text { Osteosarcoma }\end{array}$ & $\begin{array}{l}\text { National Cancer } \\
\text { Institute (NCl) }\end{array}$ \\
\hline NCT02470091 & $\|$ & $\begin{array}{l}\text { Denosumab in Treating Patients with Recurrent or } \\
\text { Refractory Osteosarcoma }\end{array}$ & 56 & $\begin{array}{l}\text { Active, not recruiting; } \\
\text { September } 30,2022\end{array}$ & $\begin{array}{l}\text { Metastatic/Recurrent/ } \\
\text { Refractory Osteosarcoma } \\
\text { Stage IV/IVA/IVB } \\
\text { Osteosarcoma AJCC v7 }\end{array}$ & $\begin{array}{l}\text { Children's } \\
\text { Oncology Group }\end{array}$ \\
\hline NCT02432274 & $1 / I 1$ & $\begin{array}{l}\text { Study of Lenvatinib in Children and Adolescents with } \\
\text { Refractory or Relapsed Solid Malignancies and Young } \\
\text { Adults with Osteosarcoma }\end{array}$ & 117 & $\begin{array}{l}\text { Active, not recruiting; } \\
\text { March 31, } 2022\end{array}$ & $\begin{array}{l}\text { Tumors } \\
\text { Solid Malignant Tumors } \\
\text { Osteosarcoma } \\
\text { Differentiated Thyroid } \\
\text { Cancer (DTC) }\end{array}$ & Eisai Limited \\
\hline NCT02243605 & $\|$ & $\begin{array}{l}\text { Cabozantinib S-malate in Treating Patients with } \\
\text { Relapsed Osteosarcoma or Ewing Sarcoma }\end{array}$ & 90 & $\begin{array}{l}\text { Active, not recruiting; } \\
\text { N.A. }\end{array}$ & $\begin{array}{l}\text { Metastatic/Recurrent/ } \\
\text { Unresectable Ewing } \\
\text { Sarcoma } \\
\text { Recurrent/Metastatic/ } \\
\text { Unresectable } \\
\text { Osteosarcoma } \\
\text { Stage III/Stage IV/Stage } \\
\text { IVA/Stage IVB } \\
\text { Osteosarcoma AJCC v7 }\end{array}$ & $\begin{array}{l}\text { National Cancer } \\
\text { Institute (NCl) }\end{array}$ \\
\hline NCT04690231 & N.A. & $\begin{array}{l}\text { Apatinib + Ifosfamide and Etoposide for Relapsed or } \\
\text { Refractory Osteosarcoma }\end{array}$ & 79 & $\begin{array}{l}\text { Active, not recruiting; } \\
\text { June 1, } 2021\end{array}$ & $\begin{array}{l}\text { Relapsed or Refractory } \\
\text { Osteosarcoma }\end{array}$ & $\begin{array}{l}\text { Peking } \\
\text { University } \\
\text { People's } \\
\text { Hospital }\end{array}$ \\
\hline NCT00470223 & III & $\begin{array}{l}\text { Combined Chemotherapy With or Without Zoledronic } \\
\text { Acid for Patients With Osteosarcoma (OS2006) }\end{array}$ & 318 & $\begin{array}{l}\text { Active, not recruiting; } \\
\text { December } 2025\end{array}$ & Osteosarcoma & UNICANCER \\
\hline NCT01953900 & 1 & $\begin{array}{l}\text { iC9-GD2-CAR-VZV-CTLs/Refractory or Metastatic GD2- } \\
\text { positive Sarcoma and Neuroblastoma (VEGAS) }\end{array}$ & 26 & $\begin{array}{l}\text { Active, not recruiting; } \\
\text { October } 31,2034\end{array}$ & $\begin{array}{l}\text { Osteosarcoma } \\
\text { Neuroblastoma }\end{array}$ & $\begin{array}{l}\text { Baylor College of } \\
\text { Medicine }\end{array}$ \\
\hline NCT02357810 & $\|$ & $\begin{array}{l}\text { Pazopanib Hydrochloride and Topotecan Hydrochloride } \\
\text { in Treating Patients With Metastatic Soft Tissue and } \\
\text { Bone Sarcomas }\end{array}$ & 178 & $\begin{array}{l}\text { Active, not recruiting; } \\
\text { June } 2022\end{array}$ & $\begin{array}{l}\text { Adult/Metastatic/Recurrent } \\
\text { Liposarcoma } \\
\text { Metastatic/Recurrent } \\
\text { Osteosarcoma } \\
\text { Recurrent } \\
\text { /Stage IV Adult Soft Tissue } \\
\text { Sarcoma }\end{array}$ & $\begin{array}{l}\text { Northwestern } \\
\text { University }\end{array}$ \\
\hline
\end{tabular}

\section{MAIN CONTENT}

\section{Antibodies as Targeting Ligands}

Antibody-drug conjugates (ADCs) are monoclonal antibodies (mAbs) that have been chemically linked to cytotoxic medications and are directed onto a cancer cell surface antigen, delivering and releasing cytotoxic chemicals at the tumor site with low systemic toxicity $(24,25)$. The FDA has currently approved a number of ADCs for clinical use in cancer therapy (26). In addition, the ADCs are well equipped for pharmacological agents in OS.

Microtubules are dynamic filamentous cytoskeletal proteins. For decades, until the advent of targeted therapy, microtubules were the only alternative to DNA as a therapeutic target in cancer (27). The most widely used pharmacological agents conjugated to antibodies are DNA-targeting and tubulin-targeting medicines, which cause DNA alkylation or double-strand break and prevent tubulin depolymerization, respectively (28).

The cytotoxic component of the dimeric protein ricin, one of the most potent and deadliest plant poisons generated from Ricinus communis seeds, is A chain (RTA). RTA has been investigated as a potential option for cancer treatment in the form of immunotoxins, as well as an approach for in vivo macrophage depletion (29). Gp72 is a cell surface antigen discovered on the surface of tumors such as osteogenic 
sarcomas (30). The anti-gp72 mAb 79IT/36 conjugates with MTX or RTA as therapeutic moieties demonstrate substantial results in treating OS (30), and better results were obtained with 79IT/36-RTA. Mice treated with the 79IT/36-RTA immunotoxin for five days, tumor growth was significantly suppressed in vivo.MM

The transmembrane protein glycoprotein non-metastatic b (gpNMB) plays a physiological role in bone differentiation and remodeling. gpNMB was found to be abundant in OS samples, implying that gpNMB could be a suitable target for antibodymediated drug delivery in OS (31). Glembatumumab vedotin is an $\mathrm{ADC}$ that combines the anti-gpNMB mAb targeting characteristics with the payload of the antimitotic microtube inhibitor MMAE. The glembatumumab vedotin has shown strong preclinical activity in in vitro and in vivo studies (32), whereas in a phase II clinical trial, it shows limited efficacy in relapsed and/or refractory OS (31).

CD184 (CXCR4) is a G-protein coupled receptor discovered on the surface of metastatic tumor cells. In patients, CXCR4 expression is a poor predictor of survival and a high predictor of tumor relapse (33). It could be efficiently absorbed when the ligand binds. A recombinant anti-CD184 mAb coupled to MMAE demonstrated significant toxicity in vitro on metastatic OS cells derived from lung metastasis (34). Similarly, an antiCXCR4 IgG-auristatin ADC demonstrated superior activity against metastatic SJSA-1-met-luc cells (OS lung metastasized cells from mouse) (35). This ADC is capable of eradicating tumors in mice receiving the immunoconjugate in a tumor xenograft lung-seeding model.

The CD248 (endosialin/TEM1) receptor is a transmembrane glycoprotein found on pericytes and fibroblasts during embryogenesis. It has been associated to tumor angiogenesis and inflammation, making it a molecular and therapeutic target for OS $(36,37)$. Two anti-endosialin ADCs were investigated in preclinical OS models (28). The anti-endosialin-MC-VC-PABC-MMAE was investigated for antitumor effectiveness in two endosialin-positive human cell lines and one sarcoma xenograft model. In vitro, a completely human anti-CD248 mAb coupled to MMAE inhibited the development of CD248 overexpressing OS cells (37).

TGF induces leucine-rich repeat containing 15 (LRRC15), a member of the Leucine-Rich Repeat superfamily, on activated fibroblasts (SMA+) and mesenchymal stem cells (MSC), which is associated with cell adhesion, invasion, and immunological responses. LRRC15 is a new cancer-associated fibroblast and mesenchymal marker that is overexpressed in OS tissue samples and is being investigated as a potential therapeutic target for ADC-based sarcoma treatment $(38,39)$. Samrotamab vedotin (ABBV-085) is an ADC made up of an anti-LRRC15 humanized IgG1 antibody (Ab1) linked to the anti-mitotic medication MMAE via a protease cleavable valine-citrulline (vc) linker. In preclinical studies, samrotamab vedotin extended event-free life in patient-derived xenograft (PDX) models (40), which may target cancer cells over LRRC15-positive cancer-associated fibroblasts due to the cell-permeable characteristics of MMAE. However, data from this unique stromal-targeting ADC's phase 1 clinical trial are mixed (38).
CD13, also known as aminopeptidase-N (APN) and alanyl aminopeptidase (ANPEP), is a metallopeptidase that was initially discovered to be a myeloid-specific hematological marker (41). A number of studies have found that CD13 plays a role in tumor growth, metastasis, and angiogenesis. By conjugating anti-CD13 monoclonal antibody (mAb) TEA1/8 to the marine chemical PM050489, a novel ADC, MI130110, was created. The MI130004 shown exceptional effectiveness in numerous murine xenograft models for OS (42).

Endothelial growth factor (VEGF) antibody was chosen as the targeted agent for the elevated production of VEGF antigen in OS cells (43), which plays a significant role in tumor angiogenesis processes. For the treatment of OS, an iron oxide nanoparticle complex conjugated to VEGF antibody and the ligand cluster of differentiation 80 (CD80) was developed (44). This combination approach would be able to target not just the extensively expressed VEGF antigen in OS cells, but also the increased expression of the surface cell receptor cytotoxic T lymphocyteassociated antigen-4 (CTLA4) (44).

The anti-CD11c mAb interacted with the CD11c receptor, which is abundant in OS cell lines. The functionalized nanoparticles of mesoporous silica nanoparticles (MSNPs) loaded with DOX and coupled with the anti-CD 11c mAb may considerably boost cellular absorption, resulting in an increased toxic and antiproliferative potential (45).

A transmembrane glycoprotein from the immunoglobulin family, activated leukocyte cell adhesion molecule (CD166/ ALCAM), can be employed as a cell surface receptor for targeting OS. In SCID mouse xenograft models, the anticancer efficacy of a mAb anti-CD166 conjugation to DOX-loaded liposomal nanoparticles targeting CD166 in OS cell lines was investigated in vivo. When compared to non-targeted medicines, these antibody-targeted medications demonstrated an increase in cytotoxicity for OS cells $(7,13)$.

The B7-H3 receptor was significantly overexpressed in OS specimens, implying the possibility of targeting this receptor for therapeutic purposes (46). ADCs targeting B7-H3 are also being developed, such m276-PBD (47). This drug carries a PBD payload containing a DNA-damaging agent and elicited full responses in two of five OS PDX models (47). MGC018 is another ADC targeting $\mathrm{B} 7-\mathrm{H} 3$ that has a DNA alkylating payload (duocarmycin) that is now being tested in OS PDX models (48). Preliminary data showed a controllable safety profile and signs of action in four of the twenty OS patients included. (Table 2 and Figure 2)

\section{Aptamers as Targeting Ligands}

Aptamers are single-stranded, synthetic DNA or RNA molecules that may fold into unique three-dimensional conformations to attach to specific target molecules with great affinity (51). Through SELEX, a repetitive in vitro process of sequential selection and amplification steps, aptamers could be selected from DNA or RNA libraries and function like "chemical antibodies". They are excellent candidates for targeted delivery of therapeutic agents due to their high selectivity and specificity, low immunogenicity, ease of synthesis with low cost and high 
TABLE 2 | Targeted delivery based on antibody as ligands.

\begin{tabular}{|c|c|c|c|}
\hline Ligands & Targets & Therapeutic agents & References \\
\hline gpNMB mAb & gpPNMB & MMAE & (32) \\
\hline anti-endosialin Ab & CD248 & MMAE & $(28,37)$ \\
\hline anti-LRRC15 humanized lgG1 kappa antibody Ab1 & LRRC15 & MMAE & $(38,40)$ \\
\hline anti-CD13 mAb & CD13 & PM050489 & $(42)$ \\
\hline anti-VEGF mAb & VEGF & $\mathrm{N} / \mathrm{A}$ & (44) \\
\hline B7-H3 mAb & CD276 & PBD/duocarmycin & $(47,48)$ \\
\hline
\end{tabular}

gPNMB, glycoprotein non-metastatic b; CD, cluster of differentiation; LRRC15, Leucine-rich repeat containing 15; VEGF, Vascular endothelial growth factor; MTX, Methotrexate; RTA, ricin toxin A chain; MMAE, monomethyl auristatin E; DOX, Doxorubicin; PBD, pyrrolobenzodiazepine.

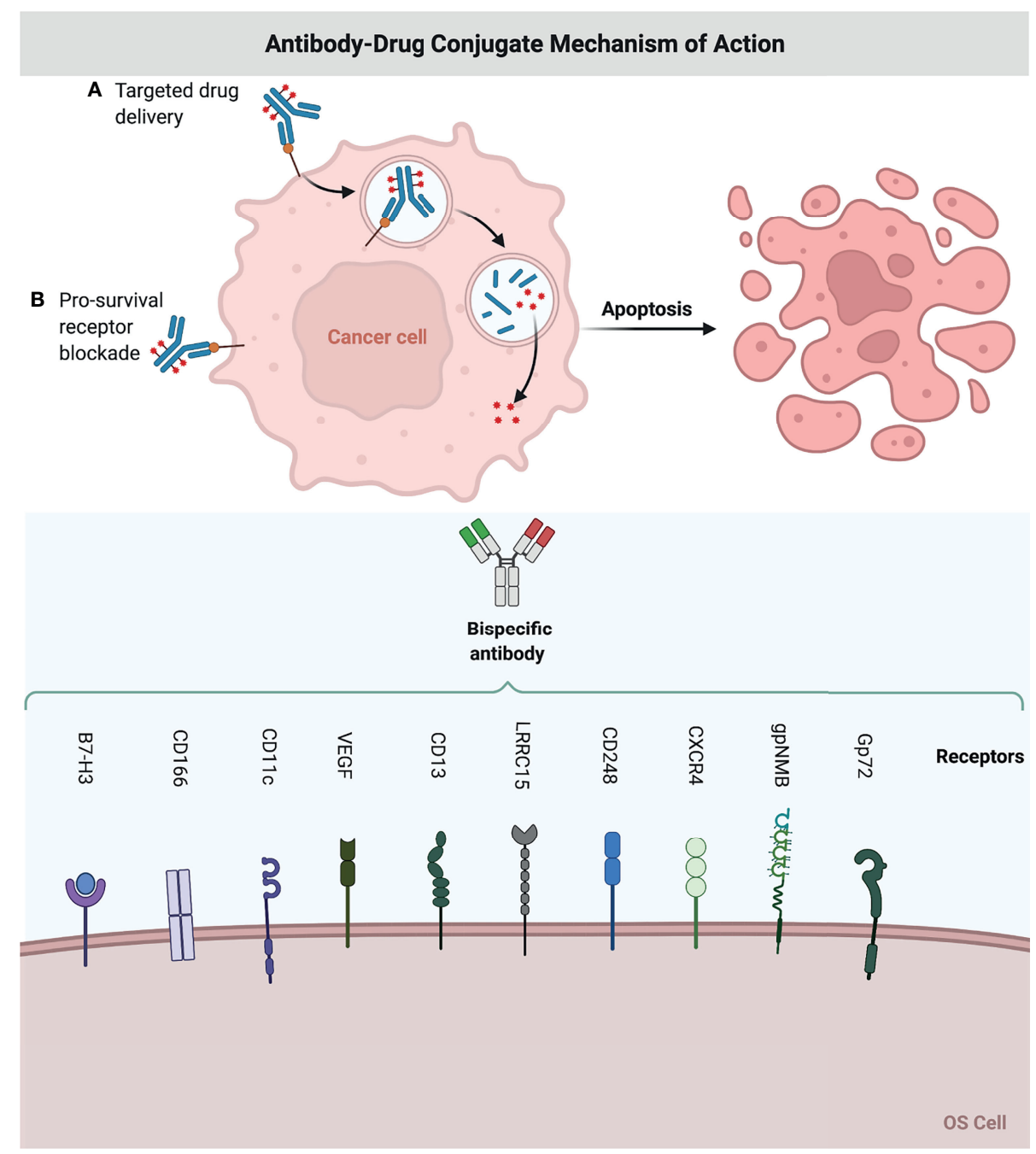

FIGURE 2 | Antibody-Drug Conjugate Mechanism of Action. A chemodrug is coupled to an antibody that specifically targets a certain OS antigen. Antibodies attach themselves to the antigens on the surface of cancerous cells. The biochemical reaction between the antibody and the target protein (antigen) triggers a signal in the OS cell, which then inhibits OS cell growth, or internalizes the antibody together with the linked chemo drug and eliminates the OS cell. This figure was created with BioRender.com. 
reproducibility, relatively rapid tissue penetration with no toxicity $(52,53)$; As a result, they are typically utilized in conjunction with anticancer medications to target tumor cell surfaces (7), which may result in more promising outcomes when compared to aptamer-free competitors. Aptamer-drug conjugates (ApDCs) are an efficient technique of reducing OS growth in vitro and in vivo due to advances in technology (54).

Vascular Endothelial Development Factor A (VEGF A) overexpression was linked to tumor growth and angiogenesis. Our research has created an OS cell-targeted aptamer (LC09) that binds to VEGFA-positive K7M2 OS cells but not to mice normal hepatocytes (AML12) or peripheral blood mononuclear cells (PBMCs). After in vivo delivery, this aptamer may reduce non-specific liver and PBMC uptake. LC09-modified lipopolymers that were loaded with CRISPR/Cas9 plasmids containing VEGFA gRNA and Cas9 showed that they were only found in OS and lung metastasis. This led to a decrease in VEGFA expression and secretion, as well as a decrease in OS malignancy and lung metastasis $(55,56)$.

CD133 is a transmembrane glycoprotein that is thought to be a cancer stem cell (CSC) marker in OS and other cancers (5759). As a result, CD133 aptamers have been employed as targeted ligands for OS CSC monitoring $(60,61)$. CD133-functionalized polymeric nanoparticles loaded with salinomycin could precisely and efficiently transport anticancer medicines to CD133 positive OS CSCs, greatly inhibiting OS development by eliminating CD133+ OS CSCs (62).

Due to the fact that amplification of the epidermal growth factor receptor (EGFR) is a frequent genetic aberration in OS, EGFR became a feasible target in the disease. EGFR aptamers were used to create OS-targeted medication delivery vehicles. Yu et al. (63) found that EGFR-SNPs, which are aptamer-conjugated polymerlipid hybrid NPs that are loaded with salinomycin, effectively stopped the formation of tumorspheres and reduced the number of CD133-positive OS CSCs. This led to an even stronger cytotoxic effect than with non-targeted SNPs and salinomycin. Chen et al. (60) engineered salinomycin-entrapped lipid-polymer nanoparticles (CESP) with CD133 and EGFR aptamers to specifically target OS cells and CSCs. CESP demonstrated superior cytotoxicity to single-targeted or untargeted salinomycin-loaded nanoparticles in OS cells and CSCs. In OSbearing mice, in vivo administration of CESP inhibited tumor growth more than other controls (Table 3 and Figure 3).

\section{Peptides as Targeting Ligands}

Peptides are short chains of amino acids linked by peptide bonds that are typically thought to be harmless due to their low immunogenicity and non-toxic metabolites (85). Peptides are thought to be swiftly broken by proteolytic enzymes and removed from the bloodstream by the liver and kidney. Different ways to modification and stabilization can be used to alter these pharmacodynamic features (86). Lipidation, which involves the incorporation of fatty acids into the peptide, is one of the most well-known principles in peptide stabilization. Fatty acids attachment could induce a more extended circulation period (87). As carrier molecules, peptide-drug conjugates (PDCs) have various advantages. The straightforward synthesis allows for reasonable optimization of side chains and backbone structures, which might result in improved binding affinities and direct influence of physicochemical attributes (88). Furthermore, their low molecular weight allows for greater penetration into solid tissues, leading in a more effective anti-tumor impact $(89,90)$.

Conventional chemotherapeutic medicines linked with peptides present greater pharmacokinetics and reduced cytotoxic. Chemotherapeutic drugs utilized in PDCs are divided into three types. The chemicals first bind to and interact with cellular DNA or DNA-protein complexes. As a result, transcription and DNA replication are disrupted, resulting in the activation of apoptosis. The cytotoxicity of the second class

TABLE 3 | Targeted delivery based on aptamers, peptides, saccharide, vitamin or bisphosphonates as ligands.

\begin{tabular}{|c|c|c|c|}
\hline Ligands & Targets & Therapeutic agents & References \\
\hline LC09 aptamer & VEGFA & plasmids encoding VEGFA gRNA and Cas9 & $(56)$ \\
\hline CD133 aptamer & CD133 & salinomycin & $(60-62)$ \\
\hline EGFR aptamer & EGFR & salinomycin & $(60,63)$ \\
\hline YSA peptide & EphA2 & DOX & (64) \\
\hline VIP peptide & VPAC1R and VPAC2R & DOX & (65) \\
\hline RGD peptide & Integrins & DOX & $(13,66,67)$ \\
\hline iRGD peptide & NRP-1 & N/A & $(68,69)$ \\
\hline $\mathrm{KRP}$ & RPS6KA2 & DOX & $(70,71)$ \\
\hline HA & CD44 & DOX & $(16,16,72)$ \\
\hline FA & FRs & MTX and/or DOX & $(73-76)$ \\
\hline Alendronate & / & DOX or PTX & $(77-79)$ \\
\hline Bisphosphonate prodrug & / & DOX & (80) \\
\hline Phospholipid & / & MDP & (81) \\
\hline Bisphosphonate & / & DOX & $(56,82)$ \\
\hline Pamidronate & hydroxyapatite & DOX & (83) \\
\hline Medronate & / & DOX & $(77,82)$ \\
\hline pamidronate & / & DOX & (84) \\
\hline
\end{tabular}

VEGFA, Vascular Endothelial Growth Factor A; EGFR, epidermal growth factor receptor; EphA2, ephrin type-A receptor 2; VIP; vasoactive intestinal peptide; RGD, Arg-Gly-Asp; $C D$, cluster of differentiation, DOX; doxorubicin; iRGD, Internalizing Arg-Gly-Asp; NRP-1, cov integrins and neuropilin-1; HA, Hyaluronic acid; FA, Folate or folic acid; FRs, folate receptors; MTX, methotrexate; MDP, Methylene diphosphonate. 


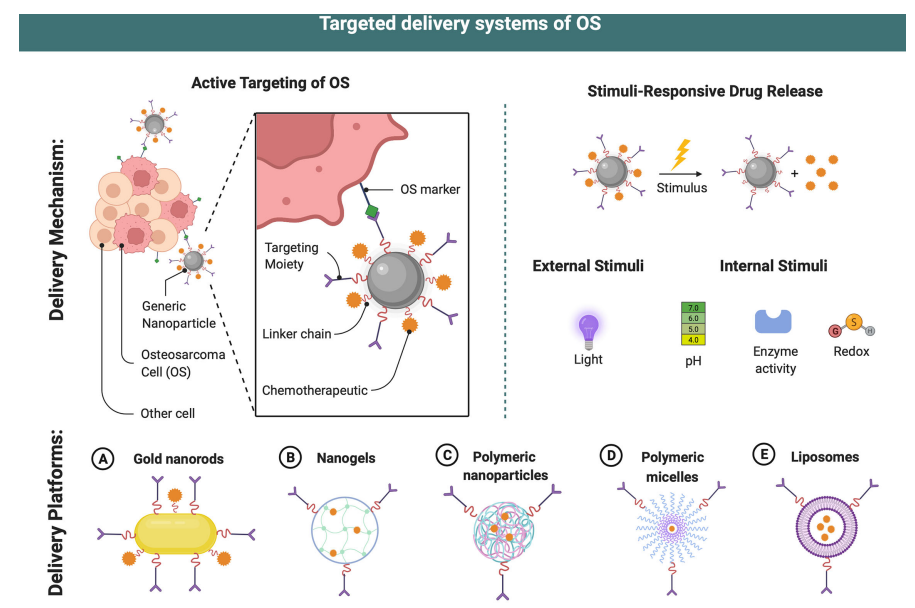

FIGURE 3 | Targeted delivery systems of OS. Different delivery systems have ideal properties for chemodrugs transport and delivery. Targeting ligands may be attached to the surface allowing an active targeting strategy and an increase in efficiency of the therapeutic payloads in OS therapy. After internalization, dissociation occurs at a proper microenvironment due to different stimuli (enzyme, redox, etc.), drug payloads are released into the cytosol of cancer cells. This figure was created with BioRender.com.

of commonly used toxophores is conveyed through blocking DNA biosynthesis. These antimetabolites include the folate derivative MTX, which inhibits the dihydrofolate reductase enzyme. Anti-mitotic drugs, which operate on microtubules, comprise the third class of chemotherapeutics (91).

By loading the same medication DOX, several new peptidebased targeted delivery systems were produced. The 12-amino acid peptide YSA (YSAYPDSVPMMS) is an ephrin A1 mimic and ligand for ephrin type-A receptor 2. (EphA2). Ephrins are a large family of tyrosine kinase receptors with well-documented roles in cancer proliferation and metastasis. They are emerging as intriguing prospective targets for cancer therapeutic methods $(92,93)$. Surface molecule EphA2a is extensively expressed in both primary and metastatic OS cells (94). In comparison to doxorubicin-free and non-targeted L-doxorubicin, DOX-loaded liposomes modified with the YSA peptide may more effectively target human Saos2 OS cells, hence increasing toxicity and cellular absorption (64). When D-aspartic acid octapeptide conjugate to micelles includes the medication DOX, it effectively promotes DOX accumulation in OS while having minimal side effects (65). The vasoactive intestinal peptide (VIP) receptors (VPAC1R and VPAC2R) are significantly expressed in Saos2. To treat OS cells, a new lipid analog (lipopeptide) coupled with VIP was created. It was proposed that the lipopeptide could be a good molecule for OS (65).

RGD, an integrin selectivity and affinity tripeptide, can be employed as an effective cancer therapeutic ligands as it can accomplish dual targeting for angiogenic endothelial cells and various tumor cells via the receptors integrin v3 and v5, respectively $(95,96)$. Integrins, which are abundantly expressed in OS cell lines, connect the extracellular matrix to the intracellular cytoskeleton to mediate cell adhesion, migration, and proliferation (97). RGD peptides have the advantage of having a low risk of immunological reactivity, being simple and affordable to synthesize, and having tight control over ligand presentation (66), as well as active OS cell targeting capacity $(13,67)$. A study by Fang et al. (13) found that RGDDOX polymeric micelles were more effective in eliminating osteoblasts than nontargeted micelles, demonstrating their ability to target and kill OS cells in vitro. Beyond RGD, internalizing Arg-Gly-Asp peptide (iRGD) combines RGD's tumor-homing ability with C-end Rule's tissue penetrating characteristic, allowing for the targeting of extravascular tumor parenchyma (68). The iRGD mechanism consists of three steps: The RGD motif binds to $\mathrm{v}$ integrins on tumor endothelial cells, and subsequently iRGD is proteolytically cleaved, gaining the ability to bind to neurophilin-1 and so achieving tissue penetration (68). Malignancies overexpressing $\mathrm{v}$ integrins and neuropilin-1 that internalize RGD (iRGD) may have increased vascular and tissue permeability (NRP-1). Increased expression of $\mathrm{v}$ integrins and NRP-1 in OS may serve as a predictor for therapeutic treatment optimization through the discovery of these two genes (69).

It was found that when KRP-DOX was combined with doxorubicin, it had multiple synergistic functions in vitro and in vivo, including good biocompatibility and biodistribution, selective accumulation of tumor tissues, and an ability to remain in tumor tissues and be internalized by cancer cells in the presence of KRP. KRP-DOX complex also evaded lysosomal breakdown and exhibited cytotoxicity in OS cells (70). OS mice were given KRP-DOX, which was shown to be more effective than either saline or DOX alone in controlling RPS6KA2 expression (71) (Table 3 and Figure 3).

\section{Saccharide as Targeting Ligands}

Proteoglycans, such as glycoproteins, are typically found on the outer surface of cancer cells, making saccharides or polysaccharides ideal ligands for OS-targeted drug delivery (98). 
Biodegradable and biocompatible linear polysaccharides, such as hyaluronic acid (HA), are naturally biodegradable and biocompatible linear polysaccharides composed of glucuronic acid and $\mathrm{N}$-acetyl d-glucosamine linked by alternating $-1,4$ and $-1,3$ glycosidic connections (99-102). The cluster determinant 44 (CD44) HA receptor is substantially expressed on MG-63 cells (103, 104), implying that HA could be a promising targeting agent for drug delivery in OS treatment. Nanocarriers with HACD44 interactions have recently been employed for tumortargeted medicine delivery due to the obvious leaky vasculature of solid tumors $(105,106)$. Redox-sensitive, HA-functionalized liposomal nanocarriers have been developed by Chi et al. (16) to improve OS therapy. It was shown that HA-modified liposomes were more able to penetrate OS MG63 cells than regular human hepatocytes. Non-HA-coated nanoparticles, on the other hand, showed a decrease in tumor formation and an increase in tumor suppression. Dox administration in OS therapy can be improved by using a CDDP-crosslinked HA nanogel (CDDPHANG) (72). Redox-sensitive and CD44-targeted liposomes were developed in another study (Chol-SS-mPEG/HA-L). Liposomes loaded with DOX were coated with noncovalent HA, showing that the easily manufactured Chol-SS-mPEG/HA-L was demonstrated to be an efficient intracellular drug delivery system that may circulate for long periods of time and release GSH-triggered cytoplasmic drug (16). Beyond HA, recently a study demonstrated that chitooligosaccharides modified liposome loaded with DOX presented a good therapeutic effect in MG63 cell-bearing nude mice (21) (Table 3 and Figure 3).

\section{Vitamin as Targeting Ligands}

Vitamins are a group of chemical molecules and nutrients that are essential for the survival of all living cells. Rapid multiplication of tumor cells, in particular, need an excess of specific vitamins, such as folate and retinoic acid (RA), in order to support their rapid development. On the tumor cell surface, the receptors involved in vitamin absorption are consequently increased when compared to normal cells. As a result, these vitamin receptors are useful target substrates for tumor-targeted medication delivery.

Coenzymes that assist the transfer of one-carbon units from donor molecules into essential biosynthetic pathways such as methionine, purine, and pyrimidine biosynthesis require folic acid (FA), also known as water-soluble vitamin B9, vitamin $\mathrm{M}$ and vitamin Bc $(107,108)$. Furthermore, it is involved in the interconversion of serine and glycine, as well as histidine catabolism (108). The principal method of cellular internalization via high affinity folate receptors (FRs) is receptor-mediated endocytosis. For ligand-based targeted treatment, folate receptor-targeted drug delivery vehicles have been revealed to transport anticancer medications into cells via receptor-mediated endocytosis, making FA an ideal alternative $(109,110)$. Through receptor-mediated endocytosis, high-affinity folate receptors (FRs) are involved in the cellular uptake of these nutrients (73). As a result, folate-functionalized nanocarriers were employed in OS-targeted treatment $(17,74,111)$. Through the interaction of FA-FRs, these nanosystems may preferentially aggregate in tumor masses and suppress tumor development.
Nanocrystalline apatite substrates coupled with FA and MTX were employed in the human SAOS-2 OS cell line (75). For OS treatment, Ai et al. (112) produced FA surface modified-titanium dioxide NPs (FA-TiNP) that displayed a superior anticancer impact compared to TiNP.

Folate-targeted gold nanorods (GNRs) are being developed as an OS treatment. To act as coating agents for GNRs, an amphiphilic polysaccharide-based graft-copolymer (INU-LAPEG-FA) and an amino derivative of the, poly(N-2hydroxyethyl)-D,L-aspartamide functionalized with folic acid (PHEA-EDA-FA) were produced. In tridimensional (3-D) OS models, the role of folate-targeted GNRs is investigated (111). Another study looked at the anticancer potential of curcumin and C6 ceramide (C6) when both were enclosed in a bilayer of liposomal nanoparticles. With C6-curcumin-FA liposomes, a substantial reduction in tumor size was reported using pegylated liposomes to enhance plasma half-life and tagging with folate (FA) for targeted distribution in vivo (17). A hybrid nanoporous microparticle ( $\mathrm{hNP}$ ) carrier based on calcium carbonate and biopolymers derivatized with FA and carrying DOX as a chemotherapeutic drug model was created and evaluated on the human OS MG-63 cell line, which demonstrated reduced cell viability (76) (Table 3 and Figure 3).

\section{Bisphosphonates as Targeting Ligands}

Hydroxyapatite is a mineral needed for bone formation. BP have a high affinity for the hydroxyapatite matrix of bone because they chelate with the divalent calcium ions $\left(\mathrm{Ca}^{2+}\right)$ in it $(15,113,114)$. BP may be a promising targeted drug for treating bone cancer since it accumulates in bone and helps to limit osteoclast recruitment and adherence to the bone matrix, which diminishes osteoclast half-life and directly suppresses its activity.

Multifunctional alendronate-drug conjugates delivery systems are an emerging notion for successful OS targeted therapy. Morton et al. (77) demonstrated that alendronate-coated nanoparticles bind and internalize fast in human OS 143B cells. Pull-(GGPNle-PTX) was created by covalently conjugating PTX with pullulan and alendronate. This pullulan-alendronate-coated medication delivery method significantly reduced breast cancer growth, migration, and angiogenesis, as well as OS bone metastases (78). Zhao et al. created a new PTX NP coated with polydopamine and grafted with alendronate as a ligand for OS targeted therapy. In vitro experiments demonstrated that targeting NPs were more hazardous to K7M2 WT OS cells than nontargeting NPs (79). In another study, alendronate (ALN) was conjugated with hyaluronic acid and DSPEPEG2000COOH via a bioreducible disulfide linker (SS) to produce an ALNHASSL loaded with DOX. In vitro, ALNHASSLL/DOX shown increased cytotoxicity to human OS MG-63 cells, as well as high and quick cellular uptake; in vivo, ALNHASSLL/DOX demonstrated excellent tumor growth suppression and prolonged survival time for orthotopic OS nude mouse models. This work showed that ALNHASSLL/DOX, which has bone-and CD44-dual-targeting properties as well as redox sensitivity, could be a potential OStargeted treatment (14).

Several BP-conjugated polymeric nanocarriers were created to carry chemotherapeutic medicines to OS, and their tumor- 
targeting and anticancer activities were tested in vivo. With the exception of free DOX or nontargeted DOX nanocarriers, these functionalized, DOX-loaded nanoparticles showed increased, longer tumor accumulation and dramatically better anticancer effectiveness $(77,82)$. Katrin et al. (80) created a DOX BP prodrug to target bone metastases. In human plasma, the prodrug exhibits rapid DOX release and appropriate stability over many hours. For about the first time, researchers found that using DOX-conjugated BP NPs reduced tumor growth $40 \%$ more effectively than using free DOX in a xenograft mouse model of human Saos-2 OS (82). It has been widely employed in the detection of bone formation and remodeling diseases, including bone cancers, using Methylene diphosphonate (MDP), a significant radiopharmaceutical agent (115). Wu et al. (81) created a phospholipid liposome coupled with MDP for in vivo targeting of OS and single photon emission computed tomography trace. By targeting OS, this method reduces toxicity to normal tissue while increasing cancer uptake (116). Recently, hydroxyapatite NPs functionalized with medronate (the smallest $\mathrm{BP})$ as a bone-targeting moiety in OS focused treatment have been reported. In vitro studies revealed that JQ1-loaded hydroxyapatite NPs effectively suppressed OS cell migration and invasion while being less hazardous to primary fibroblasts (15). Bone-targeted rather than OS targeted, BP may have the capacity to suppress osteoclasts and bone homeostasis throughout their extended stay in bone tissue $(113,117)$.

OS tumors are more likely to accumulate DOX-loaded NPs when a combination of pamidronate and NP EPR is used to target bone (83). Yin et al. (84) demonstrated the use of pamidronate-functionalized nanoparticles to transport DOX to the bone microenvironment for the targeted treatment of OS. (Table 3 and Figure 3).

\section{CONCLUSION}

OS treatment is hindered by its unknown origin, high genetic instability, large histological heterogeneity, lack of diagnostic biomarkers, high local aggressiveness, and potential for rapid spread. Certain negative effects, including tissue damage, medication resistance, and rapid blood clearance are associated with chemical treatments for OS. It is possible to improve the capacity of medications to target cancer by using active targeting strategies, such as ligand-mediated tumor targeting. An eligible ligand is critical in this progression. We reviewed commonly utilized ligands as well as other compounds in this review; these conjugates are used as emerging tools for the treatment of OS. Although significant advances in the creation of new multifunctional ligand-chemical platforms may hold enormous promise for the treatment of OS in the future, these conjugates are not yet well-developed for usage in OS patients. The majority of them are still in the cellular and animal experimental stages, and there is a lengthy transition period before they can be used in humans. However, due to improved therapeutic effects and reduced side effects, as well as the growing use of nextgeneration sequencing and emerging technologies such as single-cell sequencing, which has resulted in the discovery of a large number of OS heterogeneity and novel targets, the active targeting strategy of ligand-based chemicals is doomed to play an important role in the treatment of OS.

\section{FUTURE PERSPECTIVES}

Beyond targeted ligand-chemodrug conjugates, surgery is a significant component in the treatment of OS. OS resection is tough due to the varied placement of tumors and its closeness with adjacent tissues. It also carries a considerable risk of postoperative complications. According to Ma et al., to overcome the difficulty of precise OS resection, computer-aided design was employed to create patient-specific guidance templates for OS resection based on CT scans and magnetic resonance imaging of human OS. The guiding templates were then created using a $3 \mathrm{D}$ printing technology. The OS surgery was directed by the guiding templates, which occurred in more exact removal of the tumorous bone and placement of the bone implants, less blood loss, a shorter operation duration, and less radiation exposure throughout the procedure. Patients recovered sufficiently enough to achieve a mean Musculoskeletal Tumor Society score, according to follow-up investigations (118). Bone grafts, which can be autogenous (from the own body of patient), homogeneous (from other individuals), or xenografts (from other species), are currently used to replace bone after surgery. Because each of these techniques has its own set of limitations, research has concentrated on the use of synthetic grafts that are both safer and more cost-effective (119). To be acceptable for bone regeneration, synthetic osteo-regenerative scaffolds must be biocompatible and have the requisite porosity, degradability, compositional, and mechanical qualities (120). The above conditions are achieved by $3 \mathrm{D}$ printing. $3 \mathrm{D}$ printed scaffolds can be precisely designed to mimic bone tissue morphologically (120) and provide control over scaffold pore shape and size (121), as well as facilitate the incorporation of other functional agents within the scaffold, making them an advantageous method for fabricating implantable scaffolds for bone regeneration (120). According to Jing et al., cisplatin/hydrogel-loaded 3D-printed titanium alloy implants are safe and effective for treating OS-related bone defects and should be explored for clinical application.

However, treating bone abnormalities caused by surgical resection may not be enough. There is still a chance that some tumor cells are left over, which could lead to OS recurrence. To address this, Fu et al. 3D printed a bioceramic free carbonembedding larnite (larnite/C). The free carbon was added to aid a photothermal effect when an NIR laser was used to excite it. In vivo, the scaffold was able to kill human OS cells, slow tumor growth in naked mice, and encourage new bone production. In vitro, expression of rat bone mesenchymal stem cells may be aided by the scaffolds (122). Scaffolds made of different carbon sources, such as graphene oxide, may also have photothermal conversion characteristics. Ma et al. created graphene oxide (GO)-modified-tricalcium phosphate (GO-TCP) composite scaffolds with photothermal properties. In vitro, photothermal impacts caused considerable MG-63 OS cell death and reduced tumor growth in mice. Furthermore, as compared to plain-TCP 


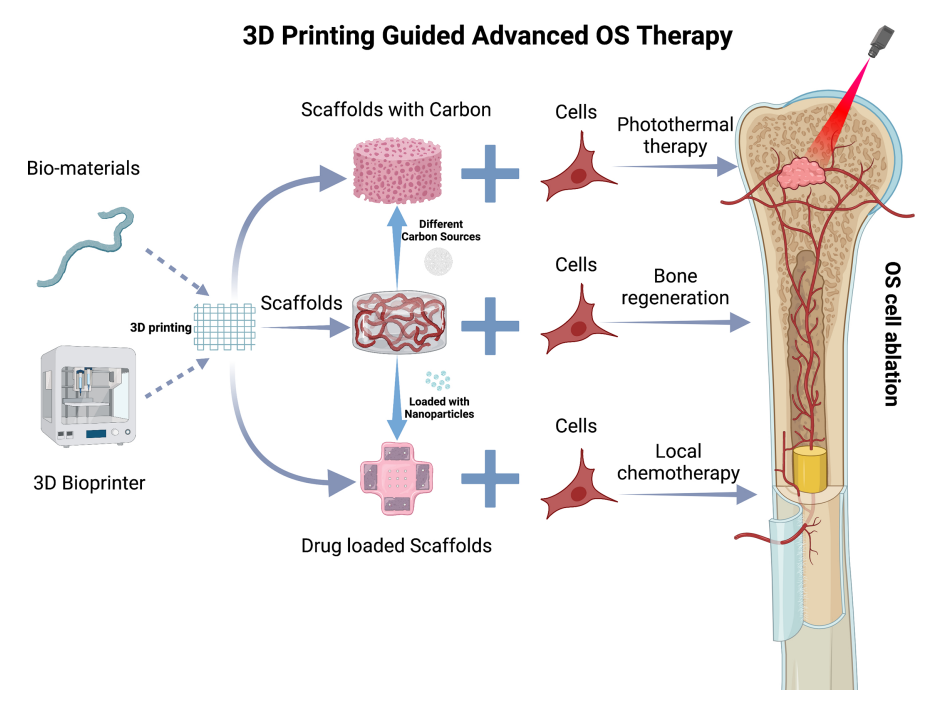

FIGURE 4 | 3D Printing guided advanced OS therapy. 3D printing scaffold and various types of carbon sources or nanocariers that may be incorporated. The nanocarriers and carbon sources are included in a 3D printed scaffold. The scaffold is then implanted into the critical defect site in the tibial due to OS resection to present bone regeneration, photothermal therapy, and local chemo release. This figure was created with BioRender.com.

scaffolds, the GO-TCP scaffolds showed superior osteogenic differentiation and new bone production (123).

Drug-loaded implants currently combine active pharmaceuticals with a biocompatible carrier and slowly release the drug after being implanted, allowing for local treatment (124). As a result, high drug concentrations at the location of interest are achieved while systemic drug exposure is reduced, avoiding undesired side effects in OS treatment (125). In this circumstance, the high degree of flexibility and controllability of 3D printing technique allows for the creation of complex forms with individualized dosages with variable release profiles, which improves local treatment. Fahimipour et al. recently developed a 3D printed gelatin/alginate/-TCP scaffold. The scaffold was subsequently coated with poly (D,L-lactic-co-glycolic acid), which encapsulated VEGF for long-term release (126). Wang et al. also created a unique technique based on 3D printed poly Llactic acid drug carriers that has the ability to realize the potential of tailored local chemotherapy in the treatment of OS and could serve as a universal platform for anti-OS therapy (124).

Among these emerging insights to facilitate OS therapies, it should be noted that $3 \mathrm{D}$ printed scaffolds pose an opportunity with high potential. They may be used to provide templates in order to achieve precise OS resection, to enhance bone regeneration, to target residual OS cells after surgical resection, and to induce sustained release platforms for drugs (Figure 4).

\section{REFERENCES}

1. Mercatelli D, Bortolotti M, Bazzocchi A, Bolognesi A, Polito L. Immunoconjugates for Osteosarcoma Therapy: Preclinical Experiences and Future Perspectives. Biomedicines (2018) 6:1-10. doi: 10.3390/ biomedicines6010019

\section{AUTHOR CONTRIBUTIONS}

CL and AL supervised and revised the manuscript. DX and ZW wrote and edited the manuscript. DG and JL provided the professional expertise. All authors contributed to the article and approved the submitted version.

\section{FUNDING}

This review is supported by the National Natural Science Foundation Council of China (82172386 and 81922081 to CL), the Croucher Foundation (CAS14BU/CAS14201 to A.L.), the Department of Education of Guangdong Province (2021KTSCX104 to CL), the 2020 Guangdong Provincial Science and Technology Innovation Strategy Special Fund (Guangdong-Hong Kong-Macau Joint Lab) (2020B1212030006 to $\mathrm{AL})$, the Guangdong Basic and Applied Basic Research Foundation (2020A1515011450 to JL), the Shenzhen Project of Science and Technology (JCYJ20190809094007719 to JL), the National Natural Science Foundation of China (82104216 to JL) and the Science, Technology and Innovation Commission of Shenzhen (JCYJ20210324104201005 to CL).

2. Hernandez Tejada FN, Zamudio A, Marques-Piubelli ML, Cuglievan B, Harrison D. Advances in the Management of Pediatric Sarcomas. Curr Oncol Rep (2021) 23(1):3. doi: 10.1007/s11912-020-00995-8

3. Corre I, Verrecchia F, Crenn V, Redini F, Trichet V. The Osteosarcoma Microenvironment: A Complex But Targetable Ecosystem. Cells (2020) 9:125. doi: $10.3390 /$ cells 9040976 
4. Meazza C, Scanagatta P. Metastatic Osteosarcoma: A Challenging Multidisciplinary Treatment. Expert Rev Anticancer Ther (2016) 16:54356. doi: 10.1586/14737140.2016.1168697

5. Isakoff MS, Bielack SS, Meltzer P, Gorlick R. Osteosarcoma: Current Treatment and a Collaborative Pathway to Success. J Clin Oncol (2015) 33:3029-36. doi: 10.1200/JCO.2014.59.4895

6. Athanasou WN, Bielack S, de Alava E, Tos APD, Ferrari S, Paulussen M, et al. Clinical Practice Guidelines Bone Sarcomas : ESMO Clinical Practice Guidelines for Diagnosis, Treatment and Follow-Up Clinical Practice Guidelines. Ann Oncol (2010) 21:204-13. doi: 10.1093/annonc/mdq223

7. Desai SA, Manjappa A, Khulbe P. Drug Delivery Nanocarriers and Recent Advances Ventured to Improve Therapeutic Efficacy Against Osteosarcoma: An Overview. J Egypt Natl Canc Inst 33(1):4. doi: 10.1186/s43046-02100059-3

8. Meazza C, Bastoni S, Scanagatta P. What is the Best Clinical Approach to Recurrent/Refractory Osteosarcoma? Expert Rev Anticancer Ther (2020) 20:415-28. doi: 10.1080/14737140.2020.1760848

9. Hattinger CM, Patrizio MP, Magagnoli F, Luppi S, Serra M. An Update on Emerging Drugs in Osteosarcoma: Towards Tailored Therapies? Expert Opin Emerg Drugs (2019) 24:153-71. doi: 10.1080/14728214.2019.1654455

10. Wang SY, Hu HZ, Qing XC, Zhang ZC, Shao ZW. Recent Advances of Drug Delivery Nanocarriers in Osteosarcoma Treatment. J Cancer (2020) 11:6982. doi: $10.7150 /$ jca. 36588

11. Bahrami B, Hojjat-Farsangi M, Mohammadi H, Anvari E, Ghalamfarsa G, Yousefi M, et al. Nanoparticles and Targeted Drug Delivery in Cancer Therapy. Immunol Lett (2017) 190:64-83. doi: 10.1016/j.imlet.2017.07.015

12. Chen J, Almo SC, Wu Y. General Principles of Binding Between Cell Surface Receptors and Multi-Specific Ligands: A Computational Study. PloS Comput Biol (2017) 13(10):e1005805.

13. Fang Z, Sun Y, Xiao H, Li P, Liu M, Ding F, et al. ScienceDirect Targeted Osteosarcoma Chemotherapy Using RGD Peptide-Installed DoxorubicinLoaded Biodegradable Polymeric Micelle. BioMed Pharmacother (2017) 85:160-8. doi: 10.1016/j.biopha.2016.11.132

14. Feng S, Wu ZX, Zhao Z, Liu J, Sun K, Guo C, et al. Engineering of Bone- and CD44-Dual-Targeting Redox-Sensitive Liposomes for the Treatment of Orthotopic Osteosarcoma. ACS Appl Mater Interf (2019) 11:7357-68. doi: 10.1021 /acsami.8b18820

15. Wu VM, Mickens J, Uskoković V. Bisphosphonate-Functionalized Hydroxyapatite Nanoparticles for the Delivery of the Bromodomain Inhibitor JQ1 in the Treatment of Osteosarcoma. ACS Appl Mater Interf (2017) 9:25887-904. doi: 10.1021/acsami.7b08108

16. Chi Y, Yin X, Sun K, Feng S, Liu J, Chen D, et al. Redox-Sensitive and Hyaluronic Acid Functionalized Liposomes for Cytoplasmic Drug Delivery to Osteosarcoma in Animal Models. J Control Release (2017) 261:113-25. doi: 10.1016/j.jconrel.2017.06.027

17. Dhule SS, Penfornis P, He J, Harris MR, Terry T, John V, et al. The Combined Effect of Encapsulating Curcumin and C6 Ceramide in Liposomal Nanoparticles Against Osteosarcoma. Mol Pharm (2014) 11:417-27. doi: $10.1021 / \mathrm{mp} 400366 \mathrm{r}$

18. Allen TM, Cullis PR. Liposomal Drug Delivery Systems: From Concept to Clinical Applications. Adv Drug Delivery Rev (2013) 65:36-48. doi: 10.1016/ j.addr.2012.09.037

19. Saraf S, Jain A, Tiwari A, Verma A, Panda PK, Jain SK. Advances in Liposomal Drug Delivery to Cancer: An Overview. J Drug Delivery Sci Technol (2020) 56:101549. doi: 10.1016/j.jddst.2020.101549

20. Singh AP, Biswas A, Shukla A, Maiti P. Targeted Therapy in Chronic Diseases Using Nanomaterial-Based Drug Delivery Vehicles. Signal Transduct Target Ther (2019) 4:1-21. doi: 10.1038/s41392-019-0068-3

21. Yin X, Chi Y, Guo C, Feng S, Liu J, Sun K, et al. Chitooligosaccharides Modified Reduction-Sensitive Liposomes: Enhanced Cytoplasmic Drug Delivery and Osteosarcomas-Tumor Inhibition in Animal Models. Pharm Res (2017) 34:2172-84. doi: 10.1007/s11095-017-2225-0

22. Yin X, Feng S, Chi Y, Liu J, Sun K, Guo C, et al. Estrogen-Functionalized Liposomes Grafted With Glutathione-Responsive Sheddable Chotooligosaccharides for the Therapy of Osteosarcoma. Drug Delivery (2018) 25:900-8. doi: 10.1080/10717544.2018.1458920

23. Haghiralsadat F, Amoabediny G, Sheikhha MH, Zandieh-doulabi B, Naderinezhad S, Helder MN, et al. New Liposomal Doxorubicin
Nanoformulation for Osteosarcoma: Drug Release Kinetic Study Based on Thermo and pH Sensitivity. Chem Biol Drug Des (2017) 90:368-79. doi: $10.1111 /$ cbdd. 12953

24. Wolska A, Tadeusz W. Safety and Tolerability of Antibody - Drug Conjugates in Cancer. Drug Saf (2019) 42:295-314. doi: 10.1007/s40264018-0775-7

25. Mukherjee A, Waters AK, Babic I, Nurmemmedov E, Glassy MC, Kesari S, et al. Antibody Drug Conjugates: Progress, Pitfalls, and Promises. Hum Antibodies (2018) 27:53-62. doi: 10.3233/HAB-180348

26. Chau CH, Steeg PS, Figg WD. Therapeutics Antibody - Drug Conjugates for Cancer. Lancet (2019) 394:793-804. doi: 10.1016/S0140-6736(19)31774-X

27. Dumontet C, Jordan MA. Microtubule-Binding Agents: A Dynamic Field of Cancer Therapeutics. Nat Rev Drug Discov (2010) 9:790-803. doi: 10.1038/ $\operatorname{nrd} 3253$

28. Polito L, Calafato G, Bortolotti M, Bolognesi A, Olivari CC, Maiello S. Antibody Conjugates for Sarcoma Therapy: How Far Along Are We? Biomedicines (2021) 9(8):978.

29. Alipour M, Pucaj K, Smith MG, Suntres ZE. Toxicity of Ricin Toxin a Chain in Rats. Drug Chem Toxicol (2013) 36:224-30. doi: 10.3109/ 01480545.2012.710624

30. Tumor H, Lines C. Sensitivity and Selectivity of Ricin Toxin A ChainMonoclonal. Cancer Res (1986) 46:5524-8.

31. Kopp LM, Malempati S, Krailo M, Gao Y, Buxton A, Weigel BJ, et al. Phase II Trial of the Glycoprotein Non-Metastatic B-Targeted Antibody-Drug Conjugate, Glembatumumab Vedotin (CDX-011), in Recurrent Osteosarcoma AOST1521: A Report From the Children's Oncology Group. Eur J Cancer (2019) 121:177-83. doi: 10.1016/j.ejca.2019.08.015

32. Kolb EA, Gorlick R, Billups CA, Hawthorne T, Kurmasheva RT, Houghton PJ, et al. Initial Testing (Stage 1) of Glembatumumab Vedotin (CDX-011) by the Pediatric Preclinical Testing Program. Pediatr Blood Cancer (2014) 61:1816-21. doi: 10.1002/pbc.25099

33. Darash-Yahana M, Pikarsky E, Abramovitch R, Zeira E, Pal B, Karplus R, et al. Role of High Expression Levels of CXCR4 in Tumor Growth, Vascularization, and Metastasis. FASEB J (2004) 18:1240-2. doi: 10.1096/ fj.03-0935fje

34. Kularatne SA, Deshmukh V, Ma J, Tardif V, Lim RKV, Pugh HM, et al. A CXCR4-Targeted Site-Specific Antibody-Drug Conjugate. Angew Chemie (2014) 126:12057-61. doi: 10.1002/ange.201408103

35. Bottaro LB. A CXCR4-Targeted Site-Specific Antibody-Drug Conjugate. Bone (2008) 23:1-7. doi: 10.1002/anie.201408103.A

36. Guo Y, Hu J, Wang Y, Peng X, Min J, Wang J, et al. Tumour Endothelial Marker 1/Endosialin-Mediated Targeting of Human Sarcoma. Eur J Cancer (2018) 90:111-21. doi: 10.1016/j.ejca.2017.10.035

37. Rouleau C, Gianolio DA, Smale R, Roth SD, Krumbholz R, Harper J, et al. Anti-Endosialin Antibody-Drug Conjugate: Potential in Sarcoma and Other Malignancies. Mol Cancer Ther (2015) 14:2081-9. doi: 10.1158/15357163.MCT-15-0312

38. Purcell JW, Tanlimco SG, Hickson J, Fox M, Sho M, Durkin L, et al. LRRC15 Is a Novel Mesenchymal Protein and Stromal Target for Antibody - Drug Conjugates. Cancer Res (2018) 78(14):4059-73. doi: 10.1158/00085472.CAN-18-0327

39. Cui J, Dean D, Wei R, Hornicek FJ, Ulmert D, Duan Z. Expression and Clinical Implications of Leucine-Rich Repeat Containing 15 (LRRC15) in Osteosarcoma. J Orthop Res (2020) 38:2362-72. doi: 10.1002/jor.24848

40. Hingorani P, Roth ME, Wang Y, Zhang W, Gill JB, Harrison DJ, et al. ABBV-085, Antibody - Drug Conjugate Targeting LRRC15, Is Effective in Osteosarcoma : A Report by the Pediatric Preclinical Testing Consortium. Mol Cancer Ther (2021) 20(3):535-41. doi: 10.1158/1535-7163.MCT-200406

41. Petrovic N, Schacke W, Gahagan JR, O'Conor CA, Winnicka B, Conway RE, et al. CD13/APN Regulates Endothelial Invasion and Filopodia Formation. Blood (2007) 110:142-50. doi: 10.1182/blood-2006-02-002931

42. Domínguez JM, Pérez-chacón G, Guillén MJ, Muñoz-alonso MJ, Somovillacrespo B, Cibrián D, et al. CD13 as a New Tumor Target for Antibody- Drug Conjugates: Validation With the Conjugate MI130110. J Hematol Oncol (2020) 7:1-15.

43. Liu Y, Zhang F, Zhang Z, Wang D, Cui B, Zeng F, et al. High Expression Levels of Cyr61 and VEGF Are Associated With Poor Prognosis in 
Osteosarcoma. Pathol Res Pract (2017) 213:895-9. doi: 10.1016/ j.prp.2017.06.004

44. Kovach AK, Gambino JM, Nguyen V, Nelson Z, Szasz T, Liao J, et al. Prospective Preliminary in Vitro Investigation of a Magnetic Iron Oxide Nanoparticle Conjugated With Ligand CD80 and VEGF Antibody As a Targeted Drug Delivery System for the Induction of Cell Death in Rodent Osteosarcoma Cells. Biores Open Access (2016) 5:299-307. doi: 10.1089/ biores. 2016.0020

45. Shahabi S, Döscher S, Bollhorst T, Treccani L, Maas M, Dringen R, et al. Enhancing Cellular Uptake and Doxorubicin Delivery of Mesoporous Silica Nanoparticles via Surface Functionalization: Effects of Serum. ACS Appl Mater Interf (2015) 7:26880-91. doi: 10.1021/acsami.5b09483

46. Wang L, Zhang Q, Chen W, Shan B, Ding Y, Zhang G, et al. B7-H3 is Overexpressed in Patients Suffering Osteosarcoma and Associated With Tumor Aggressiveness and Metastasis. PloS One (2013) 8:4-11. doi: 10.1371/ journal.pone. 0070689

47. Seaman S, Zhu Z, Saha S, Zhang XM, Yang MY, Hilton MB, et al. Eradication of Tumors Through Simultaneous Ablation of CD276/B7-H3Positive Tumor Cells and Tumor Vasculature. Cancer Cell (2017) 31:501515.e8. doi: 10.1016/j.ccell.2017.03.005

48. Scribner JA, Brown JG, Son T, Chiechi M, Li P, Sharma S, et al. Preclinical Development of MGC018, a Duocarmycin-Based Antibody-Drug Conjugate Targeting B7-H3 for Solid Cancer. Mol Cancer Ther (2020) 19:2235-44. doi: 10.1158/1535-7163.MCT-20-0116

49. Byers VS, Pimm MV, Scannen PJ, Pawluczyk I. (1987), 5042-6.

50. Adam M, Range K, Y DM. 基因的改变nih Public Access. Bone (2008) 23:1-7. doi: 10.1002/art.30444.Collagen-Induced

51. Sun $\mathrm{H}, \mathrm{Zu}$ Y. Aptamers and Their Applications in Nanomedicine. Small (2015) 11:2352-64. doi: 10.1002/smll.201403073

52. Chen K, Liu B, Yu B, Zhong W, Lu Y, Zhang J, et al. Advances in the Development of Aptamer Drug Conjugates for Targeted Drug Delivery. Wiley Interdiscip Rev Nanomed Nanobiotechnol (2017) 9(3). doi: 10.1002/ wnan. 1438

53. Moosavian SA, Sahebkar A. Aptamer-Functionalized Liposomes for Targeted Cancer Therapy. Cancer Lett (2019) 448:144-54. doi: 10.1016/ j.canlet.2019.01.045

54. Ravichandran G, Rengan AK. Aptamer-Mediated Nanotheranostics for Cancer Treatment: A Review. ACS Appl Nano Mater (2020) 3(10):954259. doi: 10.1021/acsanm.0c01785

55. Liu T, Yan Z, Liu Y, Choy E, Hornicek FJ, Mankin H, et al. CRISPR-Cas9Mediated Silencing of CD44 in Human Highly Metastatic Osteosarcoma Cells. Cell Physiol Biochem (2018) 46:1218-30. doi: 10.1159/000489072

56. Liang C, Li F, Wang L, Zhang Z, Lu A, Zhang G. Biomaterials Tumor CellTargeted Delivery of CRISPR/Cas 9 by Aptamer-Functionalized Lipopolymer for Therapeutic Genome Editing of VEGFA in Osteosarcoma. Biomaterials (2017) 147:68-85. doi: 10.1016/ j.biomaterials.2017.09.015

57. Li J, Zhong XY, Li ZY, Cai JF, Zou L, Li JM, et al. CD133 Expression in Osteosarcoma and Derivation of CD133+ Cells. Mol Med Rep (2013) 7:57784. doi: $10.3892 / \mathrm{mmr} .2012 .1231$

58. Akbari M, Shomali N, Faraji A, Shanehbandi D, Asadi M, Mokhtarzadeh A, et al. CD133: An Emerging Prognostic Factor and Therapeutic Target in Colorectal Cancer. Cell Biol Int (2020) 44:368-80. doi: 10.1002/cbin.11243

59. Aghajani M, Mansoori B, Mohammadi A, Asadzadeh Z, Baradaran B. New Emerging Roles of CD133 in Cancer Stem Cell: Signaling Pathway and miRNA Regulation. J Cell Physiol (2019) 234:21642-61. doi: 10.1002/ jcp. 28824

60. Chen F, Zeng Y, Qi X, Chen Y, Ge Z, Jiang Z, et al. Targeted Salinomycin Delivery With EGFR and CD133 Aptamers Based Dual-Ligand LipidPolymer Nanoparticles to Both Osteosarcoma Cells and Cancer Stem Cells. Nanomed Nanotechnol Biol Med (2018) 14:2115-27. doi: 10.1016/ j.nano.2018.05.015

61. Gui K, Zhang X, Chen F, Ge Z, Zhang S, Qi X, et al. Biomedicine \& Pharmacotherapy Lipid-Polymer Nanoparticles With CD133 Aptamers for Targeted Delivery of All-Trans Retinoic Acid to Osteosarcoma Initiating Cells. BioMed Pharmacother (2019) 111:751-64. doi: 10.1016/ j.biopha.2018.11.118
62. Cai G. Poly (Lactic-Co-Glycolic Acid) Nanoparticles Conjugated With CD133 Aptamers for Targeted Salinomycin Delivery to CD133 + Osteosarcoma Cancer Stem Cells. Int J Nanomed (2015) 10:2537-54.

63. Yu Z, Chen F, Qi X, Dong Y, Zhang Y, Ge ZHE, et al. Epidermal Growth Factor Receptor Aptamer - Conjugated Polymer - Lipid Hybrid Nanoparticles Enhance Salinomycin Delivery to Osteosarcoma and Cancer Stem Cells. Exp Ther Med (2018) 15(2):1247-56. doi: 10.3892/etm.2017.5578

64. Haghiralsadat F, Amoabediny G, Naderinezhad S, Nazmi K, de Boer JP, Zandieh-doulabi B, et al. EphA2 Targeted Doxorubicin-Nanoliposomes for Osteosarcoma Treatment. Pharm Res (2017) 34(12):2891-900. doi: 10.1007/ s11095-017-2272-6

65. Low SA, Yang J, Kopeček J. Bone-Targeted Acid-Sensitive Doxorubicin Conjugate Micelles as Potential Osteosarcoma Therapeutics. Bioconjug Chem (2014) 25:2012-20. doi: 10.1021/bc500392x

66. Bellis SL. Advantages of RGD Peptides for Directing Cell Association With Biomaterials. Biomaterials (2011) 32:4205-10. doi: 10.1016/ j.biomaterials.2011.02.029

67. Lu Y, Li L, Lin Z, Li M, Hu X, Zhang Y, et al. Enhancing Osteosarcoma Killing and CT Imaging Using Ultrahigh Drug Loading and NIR-Responsive Bismuth Sulfide@Mesoporous Silica Nanoparticles. Adv Healthc Mater (2018) 7:1-12. doi: 10.1002/adhm.201800602

68. Sugahara KN, Teesalu T, Karmali PP, Kotamraju VR, Agemy L, Girard OM, et al. Tissue-Penetrating Delivery of Compounds and Nanoparticles Into Tumors. Cancer Cell (2009) 16:510-20. doi: 10.1016/j.ccr.2009.10.013

69. Zhu H, Cai H, Tang M, Tang J. Neuropilin-1 is Overexpressed in Osteosarcoma and Contributes to Tumor Progression and Poor Prognosis. Clin Transl Oncol (2014) 16:732-8. doi: 10.1007/s12094-013$1141-y$

70. Yu M, Li X, Huang X, Zhang J, Zhang Y, Wang H. New Cell-Penetrating Peptide (KRP) With Multiple Physicochemical Properties Endows Doxorubicin With Tumor Targeting and Improves Its Therapeutic Index. ACS Appl Mater Interf (2019) 11:2448-58. doi: 10.1021/acsami.8b21027

71. Yu M, Wang H. Peptide KRP Conjugated With Doxorubicin Exerts AntiTumor Activity by Regulating RPS6KA2 in Osteosarcoma. (2021), 1-17.

72. Zhang Y, Wang F, Li M, Yu Z, Qi R, Ding J, et al. Self-Stabilized Hyaluronate Nanogel for Intracellular Codelivery of Doxorubicin and Cisplatin to Osteosarcoma. Adv Sci (Weinh) (2018) 5(5):1700821. doi: 10.1002/ advs. 201700821

73. Kamen BA, Capdevila A. Receptor-Mediated Folate Accumulation is Regulated by the Cellular Folate Content. Proc Natl Acad Sci USA (1986) 83:5983-7.

74. Wang R, Li D, Wang L. Nanoscale Polysaccharide Derivative as an AEG-1 siRNA Carrier for Effective Osteosarcoma Therapy. Int J Nanomed (2018) 13:857-75.

75. Ia M, Pascaud-mathieu P, Adamiano A, Montesi M, Panseri S, Marsan O, et al. Interaction of Folic Acid With Nanocrystalline Apatites and Extension to Methotrexate (Antifolate) in View of Anticancer Applications. Langmuir (2018) 34(40):12036-48. doi: 10.1021/acs.langmuir.8b02602

76. Bosio VE, Cacicedo ML, Calvignac B, León I, Beuvier T, Boury F, et al. Colloids and Surfaces B: Biointerfaces Synthesis and Characterization of CaCO 3 - Biopolymer Hybrid Nanoporous Microparticles for Controlled Release of Doxorubicin. Colloids Surfaces B Biointerf (2014) 123:158-69. doi: 10.1016/j.colsurfb.2014.09.011

77. Morton SW, Shah NJ, Quadir MA, Deng ZJ, Poon Z, Hammond PT. Osteotropic Therapy via Targeted Layer-by-Layer Nanoparticles. Adv Healthc Mater (2014) 3:867-75. doi: 10.1002/adhm.201300465

78. Bonzi G, Salmaso S, Scomparin A, Eldar-Boock A, Satchi-Fainaro R, Caliceti P. Novel Pullulan Bioconjugate for Selective Breast Cancer Bone Metastases Treatment. Bioconjug Chem (2015) 26:489-501. doi: 10.1021/bc500614b

79. Zhao L, Bi D, Qi X, Guo Y, Yue F, Wang X, et al. Polydopamine-Based Surface Modification of Paclitaxel Nanoparticles for Osteosarcoma Targeted Therapy. Nanotechnology (2019) 30(25):255101. doi: 10.1088/1361-6528/ ab055f

80. Hochdörffer K, Abu Ajaj K, Schäfer-Obodozie C, Kratz F. Development of Novel Bisphosphonate Prodrugs of Doxorubicin for Targeting Bone Metastases That are Cleaved pH Dependently or by Cathepsin B: Synthesis, Cleavage Properties, and Binding Properties to Hydroxyapatite 
as Well as Bone Matrix. J Med Chem (2012) 55:7502-15. doi: 10.1021/ jm300493m

81. Wu D, Wan M. Methylene Diphosphonate-Conjugated Adriamycin Liposomes: Preparation, Characteristics, and Targeted Therapy for Osteosarcomas In Vitro and In Vivo. BioMed Microdevices (2012) 14:497510. doi: 10.1007/s10544-011-9626-3

82. Rudnick-Glick S, Corem-Salkmon E, Grinberg I, Margel S. Targeted Drug Delivery of Near IR Fluorescent Doxorubicin-Conjugated Poly(Ethylene Glycol) Bisphosphonate Nanoparticles for Diagnosis and Therapy of Primary and Metastatic Bone Cancer in a Mouse Model. J Nanobiotechnol (2016) 14:1-11. doi: 10.1186/s12951-016-0233-6

83. Maeda H, Nakamura H, Fang J. The EPR Effect for Macromolecular Drug Delivery to Solid Tumors: Improvement of Tumor Uptake, Lowering of Systemic Toxicity, and Distinct Tumor Imaging In Vivo. Adv Drug Deliv Rev (2013) 65:71-9. doi: 10.1016/j.addr.2012.10.002

84. Yin Q, Tang L, Cai K, Tong R, Sternberg R, Yang X, et al. Pamidronate Functionalized Nanoconjugates for Targeted Therapy of Focal Skeletal Malignant Osteolysis. Proc Natl Acad Sci USA (2016) 113:E4601-9. doi: 10.1073/pnas.1603316113

85. Ahrens VM, Beck-sickinger AG. Peptides and Peptide Conjugates: Therapeutics on the Upward Path. Future Medicinal Chem (2012) 4 (12):1567-86.

86. Zhang L, Bulaj G. Converting Peptides Into Drug Leads by Lipidation. Curr Med Chem (2012) 18:1602-18.

87. Frokjaer S, Otzen DE. Protein Drug Stability : A Formulation Challenge. Nat Rev Drug Discov (2005) 4:298-306. doi: 10.1038/nrd1695

88. Erak M, Bellmann-sickert K, Els-heindl S, Beck-sickinger AG. Bioorganic \& Medicinal Chemistry Peptide Chemistry Toolbox - Transforming Natural Peptides Into Peptide Therapeutics. Bioorg Med Chem (2018) 26:2759-65. doi: 10.1016/j.bmc.2018.01.012

89. Firer MA, Gellerman G. Targeted Drug Delivery for Cancer Therapy: The Other Side of Antibodies. J Hematol Oncol (2012) 5:1. doi: 10.1186/17568722-5-70

90. Hock MB, Thudium KE, Schwabe NF. Meeting Report Immunogenicity of Antibody Drug Conjugates : Bioanalytical Methods and Monitoring Strategy for a Novel Therapeutic Modality. AAPS J (2014) 17(1):35-43. doi: 10.1208/ s12248-014-9684-6

91. Hoppenz P, Els-heindl S, Beck-sickinger AG. Peptide-Drug Conjugates and Their Targets in Advanced Cancer Therapies. Front Chem (2020) 8:1-24. doi: $10.3389 /$ fchem. 2020.00571

92. Lodola A, Giorgio C, Incerti M, Zanotti I, Tognolini M. Targeting Eph/ ephrin System in Cancer Therapy. Eur J Med Chem (2017) 142:152-62. doi: 10.1016/j.ejmech.2017.07.029

93. Saha N, Robev D, Mason EO, Himanen JP, Nikolov DB. Therapeutic Potential of Targeting the Eph/ephrin Signaling Complex. Int J Biochem Cell Biol (2018) 105:123-33. doi: 10.1016/j.biocel.2018.10.006

94. Posthumadeboer J, Piersma SR, Pham TV, van Egmond PW, Knol JC. Surface Proteomic Analysis of Osteosarcoma Identifies EPHA2 as Receptor for Targeted Drug Delivery. British J Cancer (2013) 109:2142-54. doi: $10.1038 / b j c .2013 .578$

95. Zitzmann S, Ehemann V, Schwab M. Arginine-Glycine-Aspartic Acid (RGD)-Peptide Binds to Both Tumor and Tumor-Endothelial Cells In Vivo. Cancer Res (2002) 62:5139-43.

96. Danhier F, Le BA, Préat V. RGD-Based Strategies to Target Alpha(V) Beta (3) Integrin in Cancer Therapy and Diagnosis. Mol Pharm (2012) 9:2961-73. doi: $10.1021 / \mathrm{mp} 3002733$

97. Hynes R. Integrins : A Family of Cell Surface Receptors. Cell (1987) 48:54954.

98. Jain K, Kesharwani P, Gupta U, Jain NK. A Review of Glycosylated Carriers for Drug Delivery. Biomaterials (2012) 33:4166-86. doi: 10.1016/ j.biomaterials.2012.02.033

99. Pouyani T, Prestwich GD. Functionalized Derivatives of Hyaluronic Acid Oligosaccharides: Drug Carriers and Novel Biomaterials. Bioconjug Chem (1994) 5:339-47. doi: 10.1021/bc00028a010

100. Prestwich GD, Marecak DM, Marecek JF, Vercruysse KP, Ziebell MR. Controlled Chemical Modification of Hyaluronic Acid: Synthesis, Applications, and Biodegradation of Hydrazide Derivatives. J Control Release (1998) 53:93-103. doi: 10.1016/S0168-3659(97)00242-3
101. Oh EJ, Park K, Kim KS, Kim J, Yang JA, Kong JH, et al. Target Specific and Long-Acting Delivery of Protein, Peptide, and Nucleotide Therapeutics Using Hyaluronic Acid Derivatives. J Control Release (2010) 141:2-12. doi: 10.1016/j.jconrel.2009.09.010

102. Rosso F, Quagliariello V, Tortora C, Di Lazzaro A, Barbarisi A, Iaffaioli RV. Cross-Linked Hyaluronic Acid Sub-Micron Particles: In Vitro and In Vivo Biodistribution Study in Cancer Xenograft Model. J Mater Sci Mater Med (2013) 24:1473-81. doi: 10.1007/s10856-013-4895-4

103. Eliaz RE, Nir S, Marty C, Szoka FC. Determination and Modeling of Kinetics of Cancer Cell Killing by Doxorubicin and Doxorubicin Encapsulated in Targeted Liposomes. Cancer Res (2004) 64:711-8. doi: 10.1158/00085472.CAN-03-0654

104. Kim JH, Moon MJ, Kim DY, Heo SH, Jeong YY. Hyaluronic Acid-Based Nanomaterials for Cancer Therapy. Polymers (Basel) (2018) 10:1-15. doi: $10.3390 /$ polym 10101133

105. Plattt VM, Szoka FC. Anticancer Therapeutics: Targeting Macromolecules and Nanocarriers to Hyaluronan or CD44, a Hyaluronan Receptor. Mol Pharm (2008) 5:474-86. doi: $10.1021 / \mathrm{mp} 800024 \mathrm{~g}$

106. Maeda H. Macromolecular Therapeutics in Cancer Treatment: The EPR Effect and Beyond. J Control Release (2012) 164:138-44. doi: 10.1016/ j.jconrel.2012.04.038

107. Leamon CP, Low PS. Folate-Mediated Targeting: From Diagnostics to Drug and Gene Delivery. Drug Discovery Today (2001) 6:44-51. doi: 10.1016/ S1359-6446(00)01594-4

108. Lucock M. Folic Acid: Nutritional Biochemistry, Molecular Biology, and Role in Disease Processes. Mol Genet Metab (2000) 71:121-38. doi: 10.1006/ mgme.2000.3027

109. Gupta A, Kaur CD, Saraf S, Saraf S. Targeting of Herbal Bioactives Through Folate Receptors: A Novel Concept to Enhance Intracellular Drug Delivery in Cancer Therapy. J Recept Signal Transduct (2017) 37:314-23. doi: 10.3109/ 10799893.2016.1147581

110. Wei X, Liao J, Davoudi Z, Zheng H, Chen J, Li D, et al. Folate ReceptorTargeted and Gsh-Responsive Carboxymethyl Chitosan Nanoparticles Containing Covalently Entrapped 6-Mercaptopurine for Enhanced Intracellular Drug Delivery in Leukemia. Mar Drugs (2018) 16(11):439. doi: $10.3390 / \mathrm{md} 16110439$

111. Giammona G. Near-Infrared Light Responsive Folate Targeted Gold Nanorods for Combined Photothermal-Chemotherapy of Osteosarcoma. ACS Appl Mater Interfaces (2017) 9(16):14453-69. doi: 10.1021/ acsami.7b03711

112. Ai J, Liu W, Liu B. Folic Acid-Tagged Titanium Dioxide Nanoparticles for Enhanced Anticancer Effect in Osteosarcoma Cells. Mater Sci Eng C (2017) 76:1181-7. doi: 10.1016/j.msec.2017.03.027

113. Rotman SG, Grijpma DW, Richards RG, Moriarty TF, Eglin D, Guillaume O. Drug Delivery Systems Functionalized With Bone Mineral Seeking Agents for Bone Targeted Therapeutics. J Control Release (2018) 269:88-99. doi: 10.1016/j.jconrel.2017.11.009

114. Leu C, Luegmayr E, Freedman LP, Rodan GA, Reszka AA. Relative Binding Affinities of Bisphosphonates for Human Bone and Relationship to Antiresorptive Efficacy. Bone (2006) 38:628-36. doi: 10.1016/ j.bone.2005.07.023

115. Bonewald LF, Harris SE, Rosser J, Dallas MR, Dallas SL, Camacho NP, et al. Von Kossa Staining Alone is Not Sufficient to Confirm That Mineralization In Vitro Represents Bone Formation. Calcif Tissue Int (2003) 72:537-47. doi: $10.1007 /$ s00223-002-1057-y

116. Yu L, Cai L, Hu H, Zhang Y. Experiments and Synthesis of Bone-Targeting Epirubicin With the Water-Soluble Macromolecular Drug Delivery Systems of Oxidized-Dextran. J Drug Target (2014) 22:343-51. doi: 10.3109/ 1061186X.2013.877467

117. Li CJ, Liu XZ, Zhang L, Chen LB, Shi X, Wu SJ, et al. Advances in BoneTargeted Drug Delivery Systems for Neoadjuvant Chemotherapy for Osteosarcoma. Orthop Surg (2016) 8:105-10. doi: 10.1111/os.12238

118. Ma L, Zhou Y, Zhu Y, Lin Z, Wang Y, Zhang Y, et al. 3D-Printed Guiding Templates for Improved Osteosarcoma Resection. Sci Rep (2016) 6:2-10. doi: $10.1038 /$ srep23335

119. Martin V, Bettencourt A. Bone Regeneration: Biomaterials as Local Delivery Systems With Improved Osteoinductive Properties. Mater Sci Eng C (2018) 82:363-71. doi: 10.1016/j.msec.2017.04.038 
120. Wang C, Huang W, Zhou Y, He L, He Z, Chen Z, et al. 3D Printing of Bone Tissue Engineering Scaffolds. Bioact Mater (2020) 5:82-91. doi: 10.1016/ j.bioactmat.2020.01.004

121. Ghorbani F, Li D, Ni S, Zhou Y, Yu B. 3D Printing of Acellular Scaffolds for Bone Defect Regeneration: A Review. Mater Today Commun (2020) 22:100979. doi: 10.1016/j.mtcomm.2020.100979

122. Fu S, Hu H, Chen J, Zhu Y, Zhao S. Silicone Resin Derived Larnite/C Scaffolds via 3D Printing for Potential Tumor Therapy and Bone Regeneration. Chem Eng J (2020) 382:122928. doi: 10.1016/j.cej.2019.122928

123. Ma H, Jiang C, Zhai D, Luo Y, Chen Y, Lv F, et al. A Bifunctional Biomaterial With Photothermal Effect for Tumor Therapy and Bone Regeneration. Adv Funct Mater (2016) 26:1197-208. doi: 10.1002/adfm.201504142

124. Wang Y, Sun L, Mei Z, Zhang F, He M, Fletcher C, et al. 3D Printed Biodegradable Implants as an Individualized Drug Delivery System for Local Chemotherapy of Osteosarcoma. Mater Des (2020) 186:108336. doi: 10.1016/ j.matdes.2019.108336

125. Zhou H, Hernandez C, Goss M, Gawlik A, Exner AA. Biomedical Imaging in Implantable Drug Delivery Systems. Curr Drug Targets (2015) 16(6):672-82

126. Fahimipour F, Rasoulianboroujeni M, Dashtimoghadam E, Khoshroo K, Tahriri M, Bastami F, et al. 3D Printed TCP-Based Scaffold Incorporating
VEGF-Loaded PLGA Microspheres for Craniofacial Tissue Engineering. Dent Mater (2017) 33:1205-16. doi: 10.1016/J.DENTAL.2017.06.016

Conflict of Interest: The authors declare that the research was conducted in the absence of any commercial or financial relationships that could be construed as a potential conflict of interest.

Publisher's Note: All claims expressed in this article are solely those of the authors and do not necessarily represent those of their affiliated organizations, or those of the publisher, the editors and the reviewers. Any product that may be evaluated in this article, or claim that may be made by its manufacturer, is not guaranteed or endorsed by the publisher.

Copyright (c) 2022 Xie, Wang, Li, Guo, Lu and Liang. This is an open-access article distributed under the terms of the Creative Commons Attribution License (CC BY). The use, distribution or reproduction in other forums is permitted, provided the original author(s) and the copyright owner(s) are credited and that the original publication in this journal is cited, in accordance with accepted academic practice. No use, distribution or reproduction is permitted which does not comply with these terms. 